\title{
Microcontroller Based Efficient Multilevel Inverter Using SVPWM Technique
}

\author{
Shireesha Thummala ${ }^{1}$,E.Swarnalatha ${ }^{2}$, B Uma Suramanjhari ${ }^{3}$ N Sudheer kumar ${ }^{4}$ \\ ${ }^{I}$ (ECE, Vignan's Institute of Technology and Aeronautical Engineering, Vignan Hills,Hyderabad,India) \\ ${ }^{2}$ (ECE, Vignan's Institute of Technology and Aeronautical Engineering, Vignan Hills, Hyderabad,India) \\ ${ }^{3}$ (EEE, Vignan's Institute of Technology and Aeronautical Engineering, Vignan Hills, Hyderabad,India) \\ ${ }^{4}$ (ECE, Vignan's Institute of Technology and Aeronautical Engineering, Vignan Hills, Hyderabad,India)
}

\begin{abstract}
This paper presents the implementation of microcontroller based multilevel inverter using SVPWM technique. The output harmonic content is reduced by using multilevel inverter. The voltage and power increase with increase in the number of levels of inverter. The switching angle for the pulse is selected in such way to reduce the harmonic distortion. The model of the multilevel inverter system is developed with space vector modulation (SVM) strategy to run the induction motor. Space vector modulation technique is used to reduce the harmonics. Space vector modulation is required due to vector selection in $d-q$ stationary reference frame.SVPWM technique proposed here can also work in over modulation range. The simulation work for space vector modulation and sinusoidal pulse width modulation (SPWM) are done and the results are compared. The $T H D$ content is reduced in case of SVM technique. In hardware, microcontroller based multilevel inverter is implemented. The hardware is implemented for a two level inverter. The multilevel inverter output has reduced harmonic level. A microcontroller based gating circuit generates the pulses required by the inverter. The multilevel inverter hardware is successfully fabricated and tested.
\end{abstract}

Keywords: GUI,SVM,SPWM,SVPWM,VSI

\section{Introduction}

Multilevel inverters have emerged as a very important alternative in the area of high power mediumvoltage applications.The modulation techniques available for multilevel inverters are sinusoidal pulse width modulation, Space Vector Modulation.The most widely used technique for the implementation of multilevel inverters is Space vector pulse width modulation as it has many advantages over sinusoidal pulse width modulation.

Space vector modulation has advantages over Sinusoidal modulation in terms of efficient utilization of DC bus voltage, less total harmonic distortion(THD) and also it can work with higher modulation indices. This paper implements a Two level inverter using SVPWM method.It can be extended to a n-level inverter.A Two level inverter is simulated using Simulink.Simulink is a software package for modeling, simulating, and analyzing dynamic systems. For modeling, Simulink provides a graphical user interface (GUI) for building models as block diagrams, using click-and-drag mouse operations. Simulink includes a comprehensive block library of sinks, sources, linear and nonlinear components, and connectors. One can also customize and create their own blocks. The microcontroller used here is Programmable Interfacing Controller PIC 16F877A which is used to generate the gating pulses which will be given to a two level inverter.

\section{1}

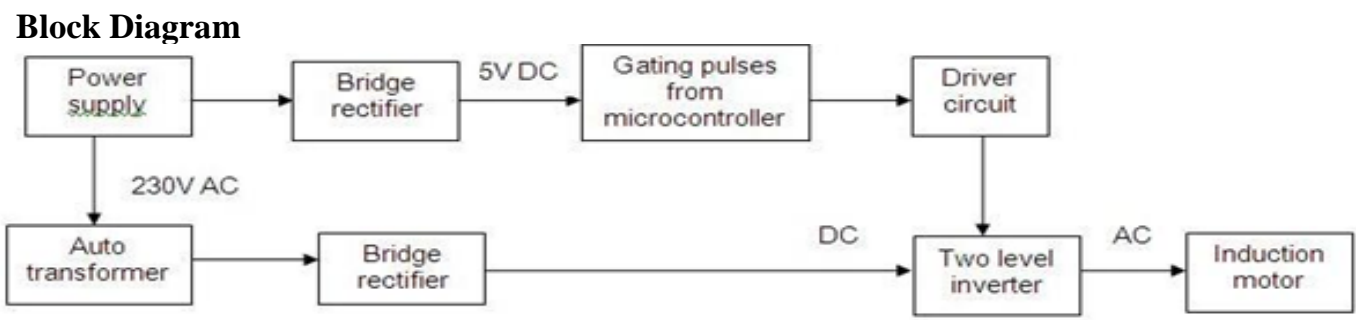

Fig. 1 General Block Diagram of Hardware

Fig. 1 shows the general block diagram of this paper. From the power supply unit, $5 \mathrm{~V}$ dc supply is obtained by using a bridge rectifier and given to the controller and $230 \mathrm{~V}$ ac supply is given to the autotransformer which is rectified and given to the inverter power circuit. From the controller, the generated gating pulses are given to the driver circuit. From the driver circuit gating pulses are given to the inverter circuit. The inverter converts dc supply to ac supply and drives the induction motor. 


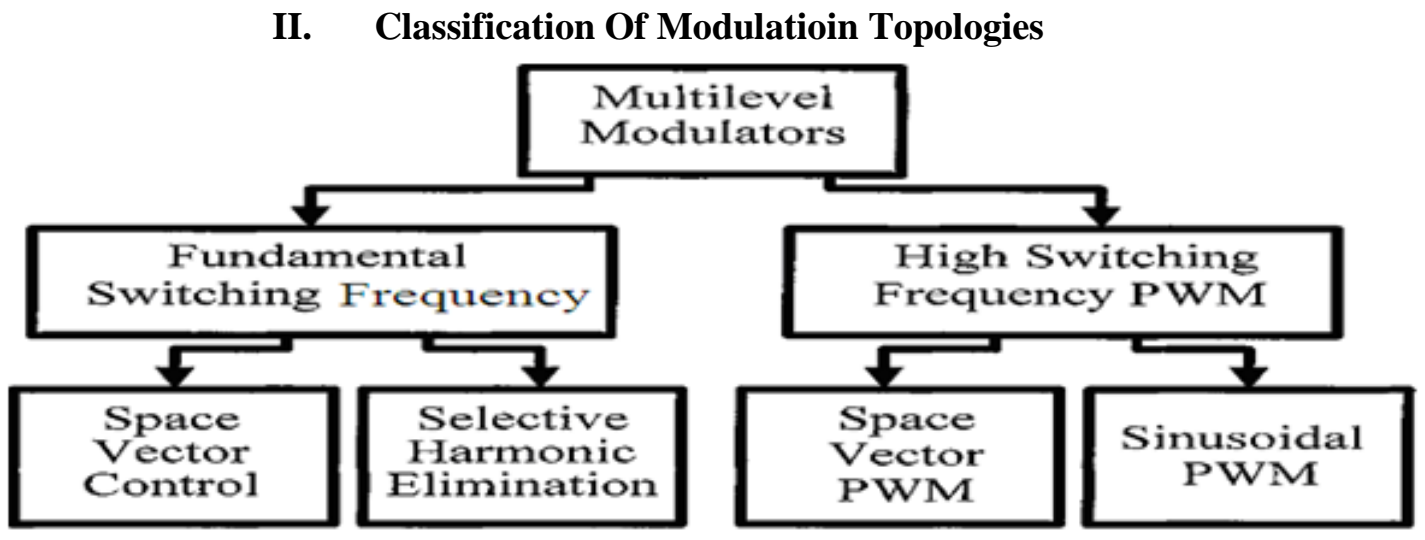

Fig. 2 Classification of Multilevel Modulation Methods

Several multicarrier techniques have been developed to reduce the distortion in multilevel inverters, based on the classical SPWM with triangular carriers. It uses the principle of comparing a sinusoidal reference with a triangular carrier signal. A number of $\mathrm{N}_{\mathrm{c}}$ cascaded cells in one phase with their carriers shifted by an angle $\theta_{c}=360^{\circ} / \mathrm{N}_{\mathrm{c}}$ and using the same control voltage produce a load voltage with the smallest distortion. SPWM uses the method of comparing high frequency triangular carrier signal with 3 sinusoidal reference signals. However, there are obvious drawbacks or weaknesses of SPWM technique which directly affect the efficiency of the overall system. In order to overcome these drawbacks, a newer and more advanced technique is introduced known as space vector modulation (SVM) which is also aimed to increase the system efficiency.

\subsection{Principle Of Space Vector Modulation}

Basically, SVM uses the method of taking all 3 modulating signals into account simultaneously within a 2D reference frame (in d-q axis or complex form). In other words, SVM is more sophisticated and it offers more voltage output (approximately 15\% more) if compared to SPWM, and thus DC voltage utilization is increased by using SVM.Space vector modulation (SVM) refers to a special switching sequence which is based on the upper switches of a three phase voltage source inverter (VSI). Theoretically, SVM treats a sinusoidal voltage as a phasor or amplitude vector which rotates at a constant angular frequency, $\omega$. This amplitude vector is represented in d-q plane where it denotes the real and imaginary axes. As SVM treats all three modulating signals or voltages as one single unit, the vector summation of three modulating signals or voltages are known as the reference voltage, $V_{\text {ref }}$ which is related to the magnitude of output voltage of the eight switching topologies of a three phase VSI. It is important to note that the aim of SVM is to approximate the reference voltage vector, $\mathrm{V}_{\text {ref }}$ using the eight switching topologies. The 8 switching topologies can also be represented in the form of space vector hexagon, where it is divided into 6 sectors and each sector is separated with a phase shift of $60^{\circ}$. Reference voltage vector, $\mathrm{V}_{\text {ref }}$ derived from the vector summation of all three modulating voltages is rotated in anti-clockwise direction from one sector to another at a constant angular speed, $\omega t$ for steady state operating condition. Another important note is that the time taken by reference voltage vector to complete one revolution is equal to the fundamental period of the output voltage.

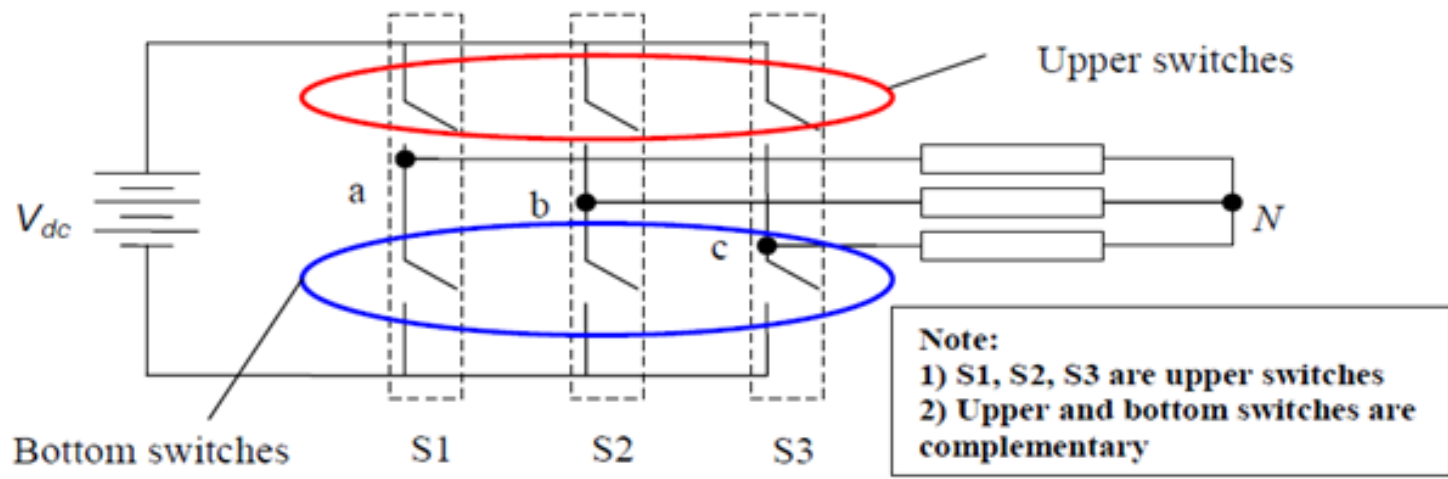

Fig. 3 Three Phase Voltage Source Inverter 
To implement the space vector PWM, the voltage equations in the abc reference frame can be transformed into the stationary d-q reference frame that consists of the horizontal (d) and vertical (q) axes.

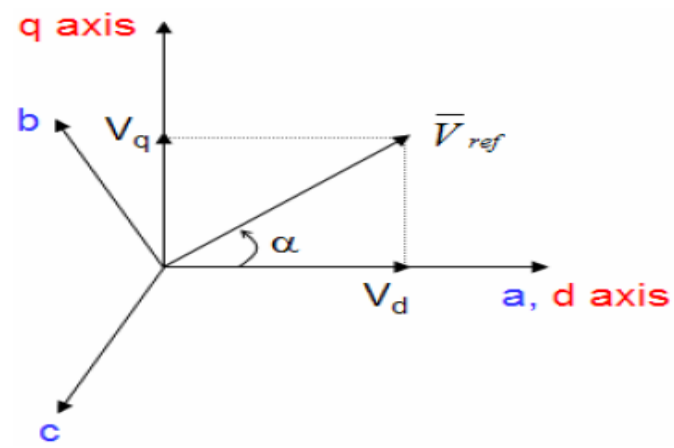

Fig. 4 The Relationship of abc Reference Frame and Stationary d-q Reference Frame

This transformation is equivalent to an orthogonal projection of $[a, b, c]{ }^{t}$ onto the two-dimensional perpendicular to the vector $[1,1,1]^{\mathrm{t}}$ (the equivalent $\mathrm{d}$-q plane) in a three-dimensional coordinate system. As a result, six non-zero vectors and two zero vectors are possible. Six nonzero vectors $\left(\mathrm{V}_{1}-\mathrm{V}_{6}\right)$ shape the axes of a hexagonal as depicted in Fig. 4.4, and feed electric power to the load. The angle between any adjacent two nonzero vectors is 60 degrees. Meanwhile, two zero vectors $\left(\mathrm{V}_{0}\right.$ and $\left.\mathrm{V}_{7}\right)$ are at the origin and apply zero voltage to the load. The eight vectors are called the basic space vectors and are denoted by $\mathrm{V}_{0}, \mathrm{~V}_{1}, \mathrm{~V}_{2}, \mathrm{~V}_{3}, \mathrm{~V}_{4}, \mathrm{~V}_{5}, \mathrm{~V}_{6}$, and $\mathrm{V}_{7}$. The same transformation can be applied to the desired output voltage to get the desired reference voltage vector $\mathrm{V}_{\text {ref }}$ in the $\mathrm{d}-\mathrm{q}$ plane. The objective of space vector PWM technique is to approximate the reference voltage vector $\mathrm{V}_{\text {ref }}$ using the eight switching patterns. One simple method of approximation is to generate the average output of the inverter in a small period, $\mathrm{T}$ to be the same as that of $\mathrm{V}_{\text {ref }}$ in the same period.

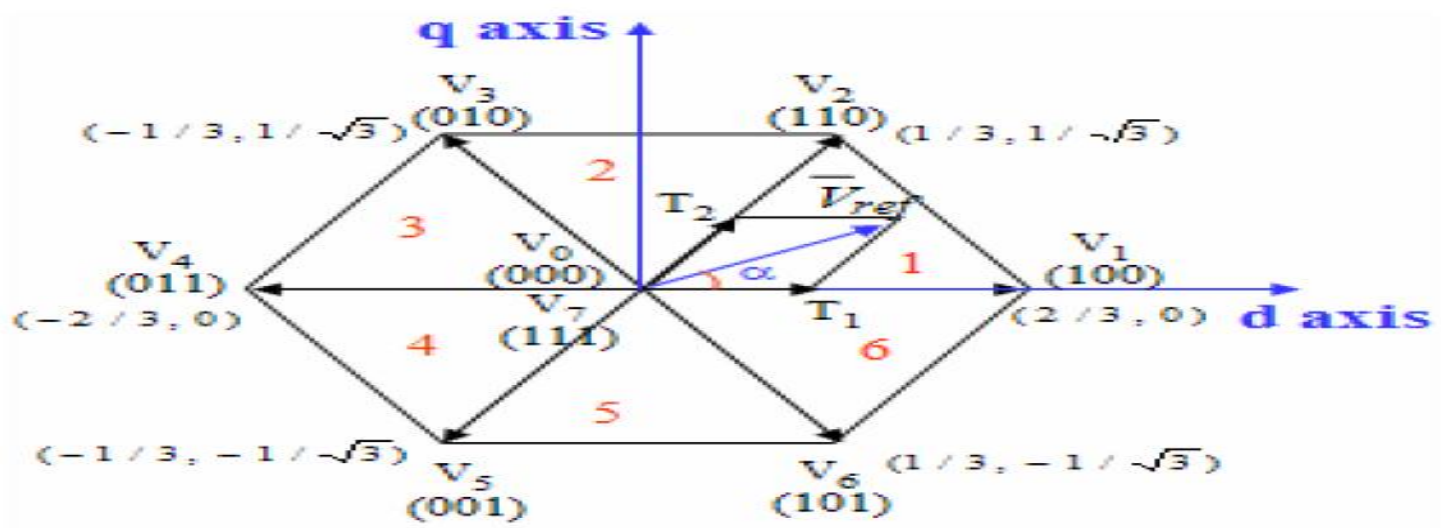

Fig. 5 Basic Switching Vectors and States

\subsection{Simulation Of Two Level Inverter Using Svpwm Method}

\section{Simulation Results}

Table 1. Specifications of the Subsystem in SVPWM Method

\begin{tabular}{|c|c|}
\hline SPECIFIC.ATIONS & VALLES \\
\hline Modulation index & 0.8 \\
\hline Phase (degree) & 30 \\
\hline Frequency $(\mathrm{Hz})$ & 50 \\
\hline Sample time $(\mathrm{s})$ & $2 \mathrm{e}-6$ \\
\hline
\end{tabular}




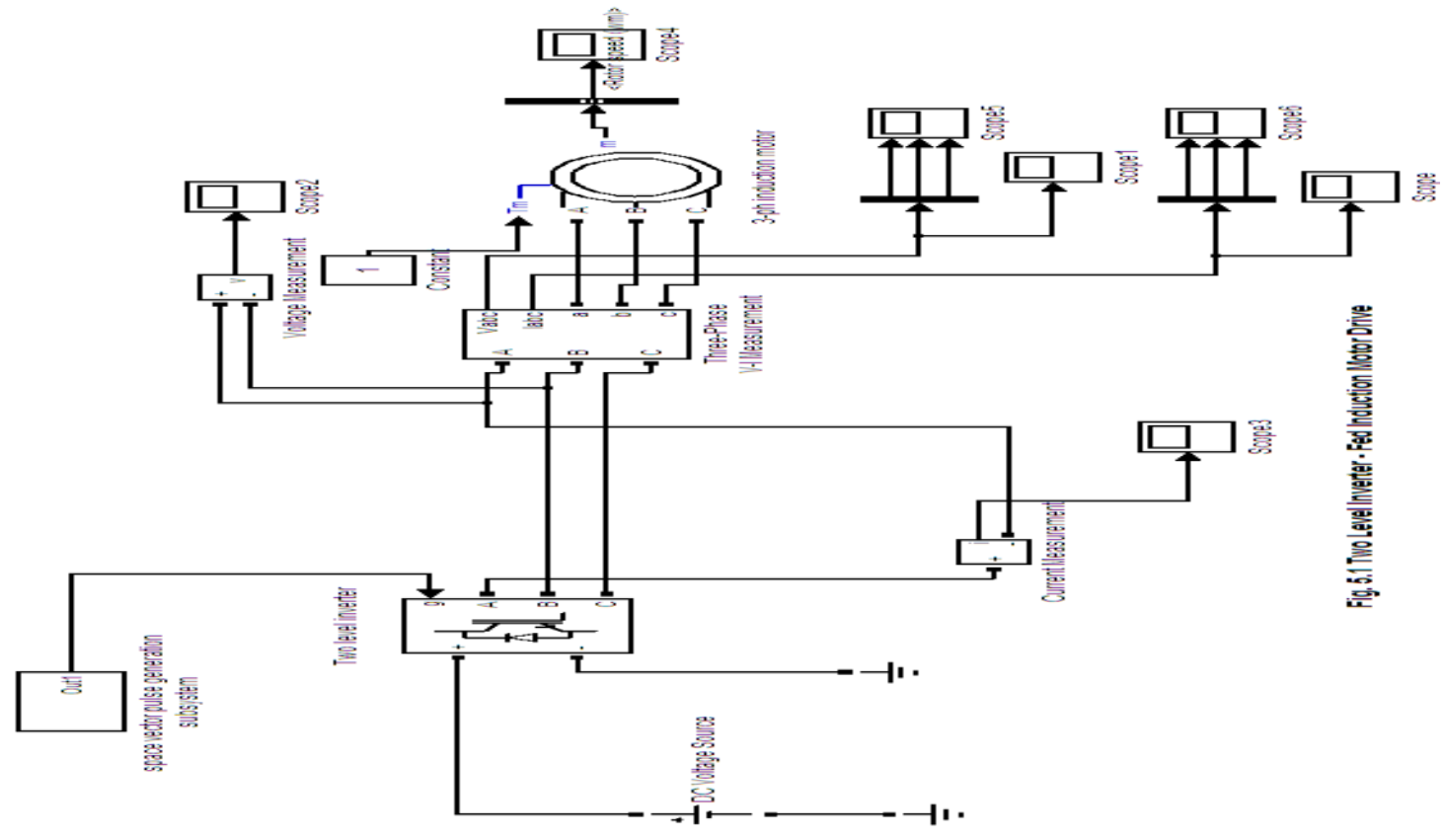

圆要

Fig. 6 Two level inverter circuit using SVPWM method

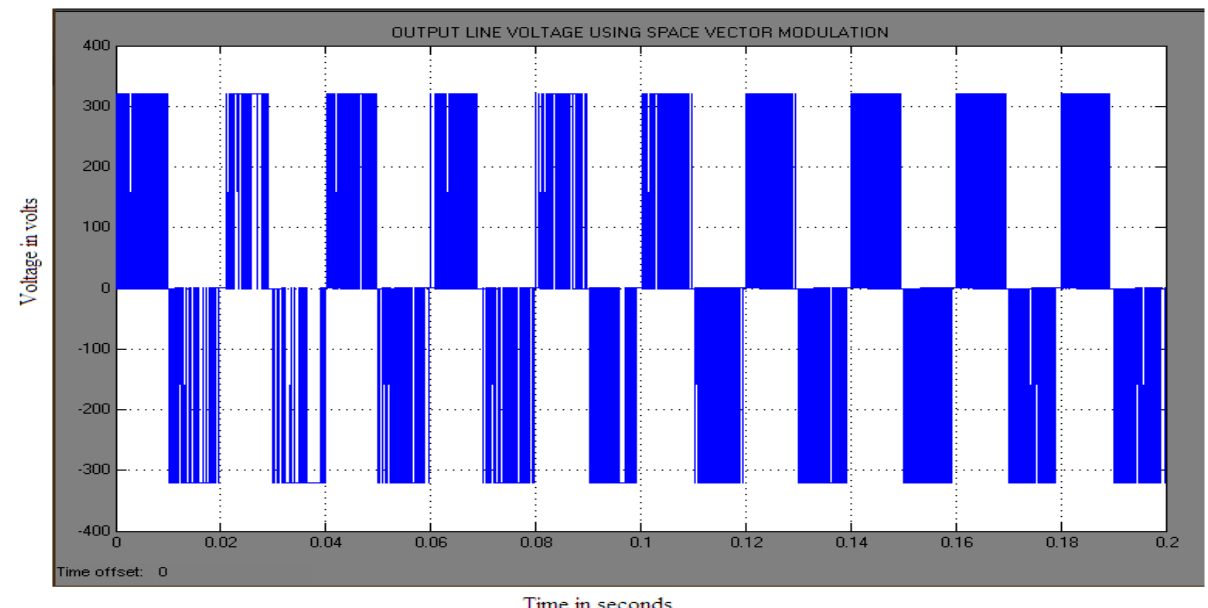

Fig. 7 Output Voltage Waveform Using SVPWM Method
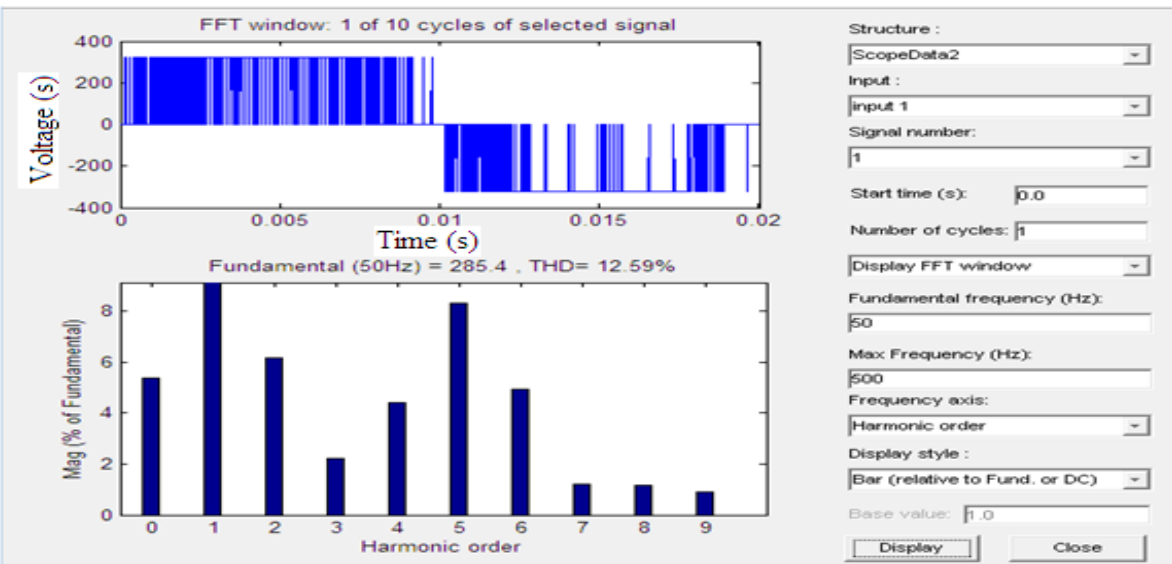

Fig. 8 THD Analysis Using SVPWM Method 


\subsection{Simulation Of Two Level Inverter Using Spwm Method}

Table 2. Specifications of the Subsystem in SPWM Method

\begin{tabular}{|c|c|}
\hline SPECIFICATIONS & VALLES \\
\hline Modulation index & 0.4 \\
\hline Phase (degree) & 0 \\
\hline Frequency (Hz) & 60 \\
\hline Sample time (S) & $2 \mathrm{e}-6$ \\
\hline
\end{tabular}

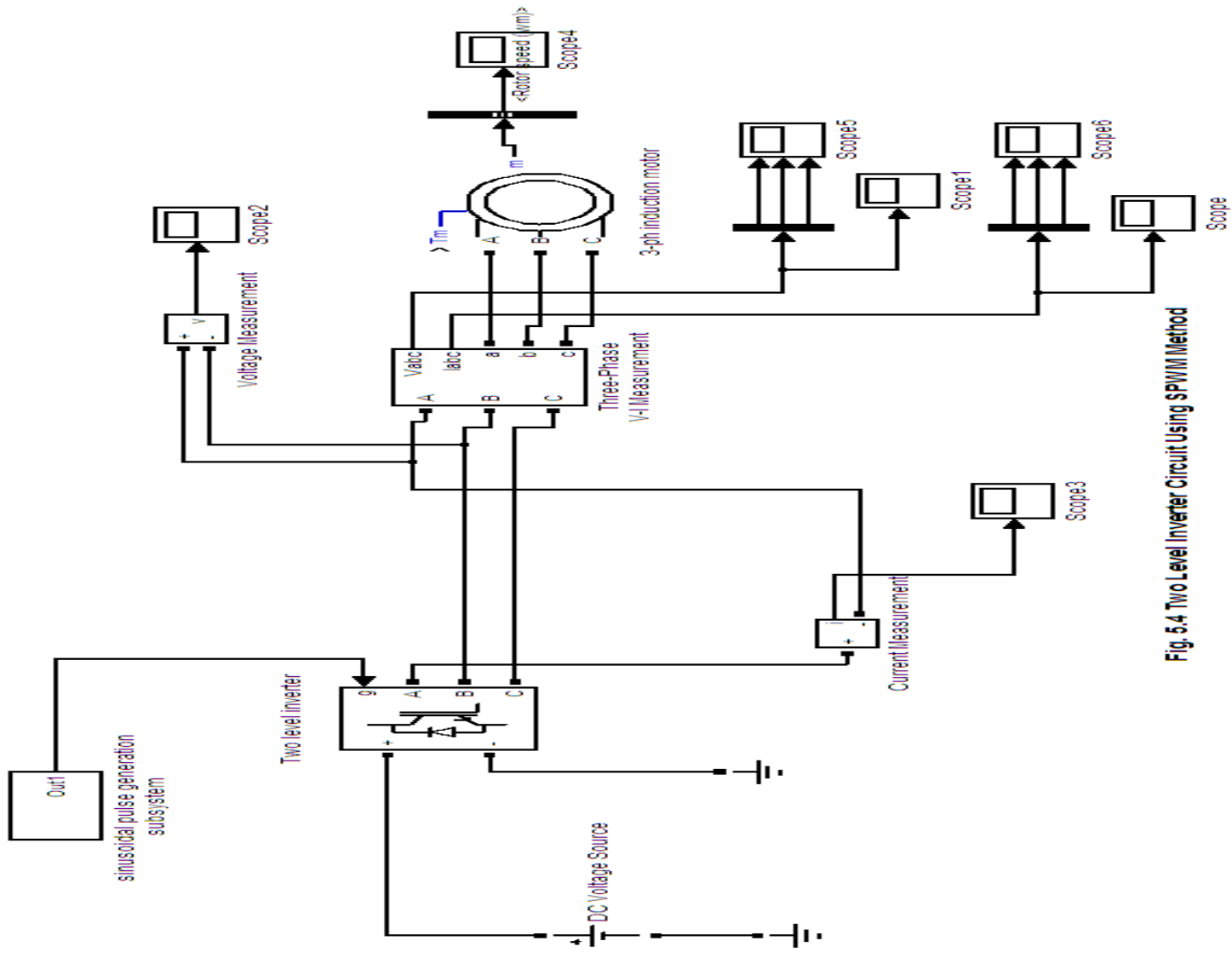

Fig. 9 Two level inverter circuit using SPWM method

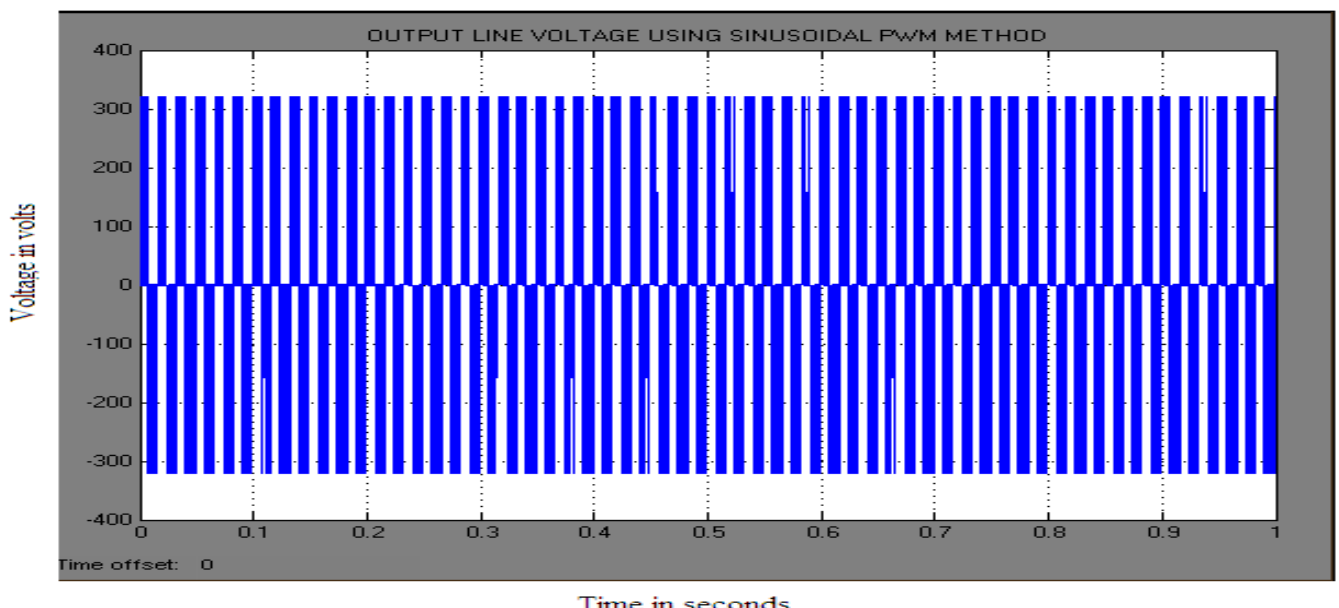

Fig. 10 Output Voltage Waveform Using SPWM Method 

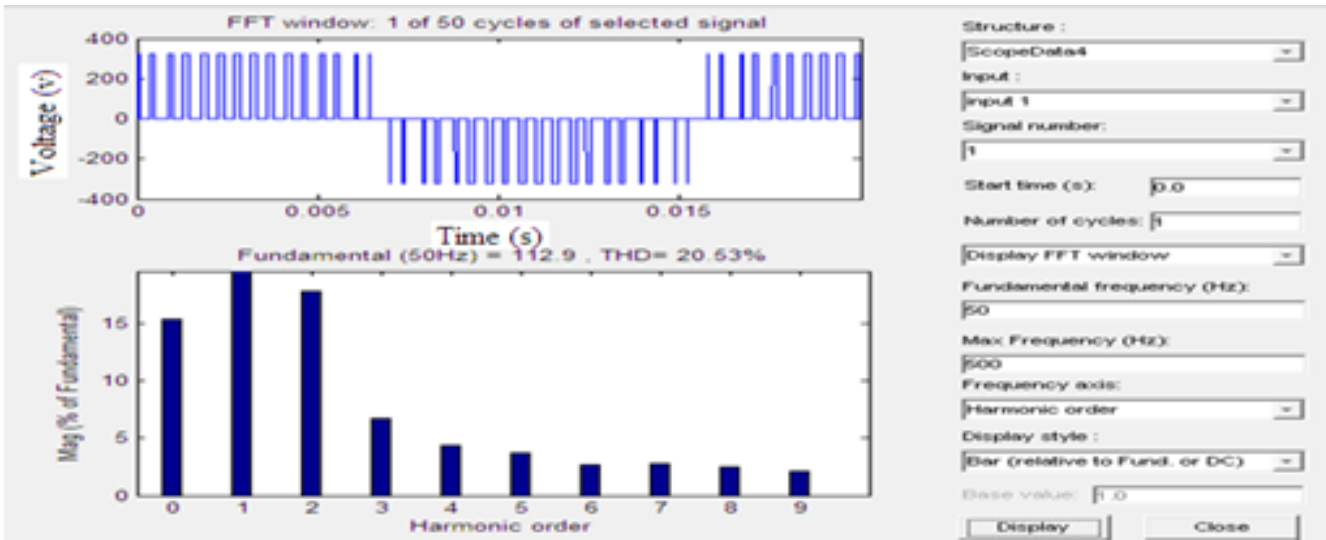

Fig. 11 THD Analysis Using SPWM Method

Table 2 Comparison of THD Analysis

\begin{tabular}{|c|c|}
\hline MODULATION TECHNTQU & VOLTAGE THD $(\%)$ \\
\hline Space vector pulse width modulation & $12.59 \%$ \\
\hline Sinusoidal pulse width modulation & $20.53 \%$ \\
\hline
\end{tabular}

\section{Hardware Results}

The hardware results are taken using digital oscilloscope and the software known as Wavestar.The pulse waveform from the controller to the inverter upper and lower level switches, the output line to line voltage waveform is taken and the THD content is calculated.

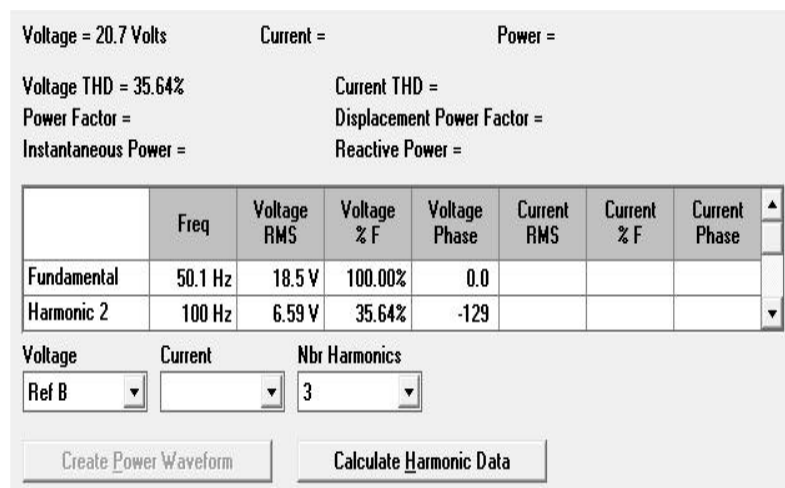

Fig. 12 Voltage Waveform - THD Calculation

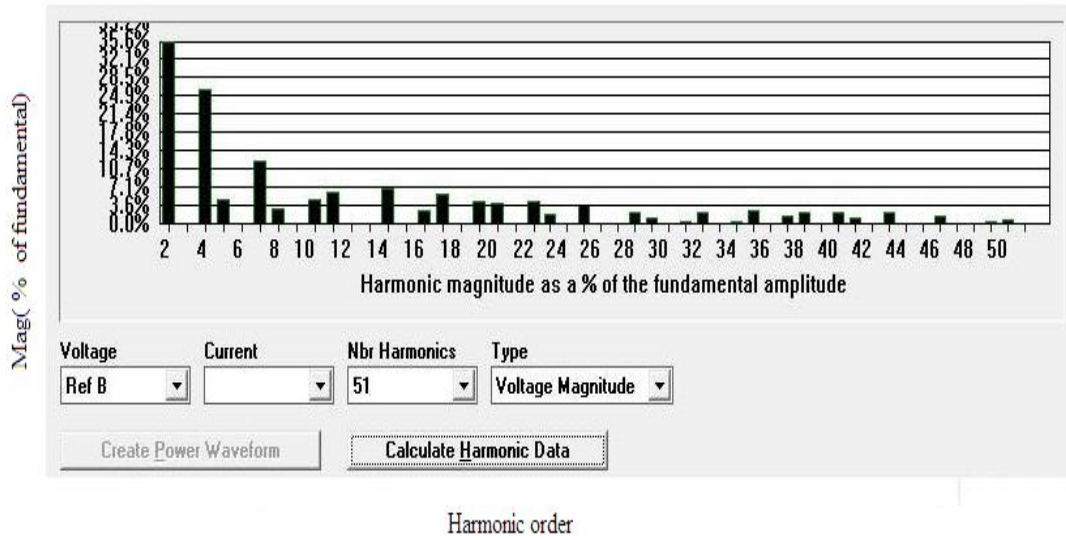

Fig. 13 Output Voltage Harmonic Content Waveform 


\section{Conclusion}

Multilevel inverter using SVPWM technique is simulated using MATLAB Simulink. The modulation technique used here is space vector pulse width modulation (SVPWM). The simulation work is done for both space vector modulation and the sinusoidal pulse width modulation. SVM technique utilizes DC bus voltage more efficiently and generates less harmonic distortion in a three phase voltage source inverter. Compared with sinusoidal pulse width modulation it can work with a higher modulation index $(\mathrm{m}>1)$ and the harmonic content of the inverter voltage is less in the space vector pulse width modulation than in sinusoidal pulse width modulation. The THD content is $12.59 \%$ in space vector technique.

In hardware, a microcontroller based multilevel inverter fed induction motor system is fabricated and tested. The PIC microcontroller 16F877A is used to generate the pulses. The total harmonic distortion (THD) is also measured from the two level inverter waveform using Wavestar and the THD measured is nearly $35 \%$. As the number of levels increases the THD content gets reduced. The multilevel inverter with space vector modulation is an efficient technique in the reduction of THD.

\section{References}

[1]. Zhou, K., and Wang, D.: 'Relationship between space-vector modulation and three-phase carrier-based PWM: A comprehensive analysis', IEEE Trans. Ind. Electron., 2002, 49, (1), pp. 186-196.

[2]. Holtz, J., Lotzkat, W., and Khambadkone, A.: 'On continuous control of PWM inverters in over-modulation range including sixstep mode', IEEE Trans. Power Electron., 1993, 8, (4), pp. 546-553

[3]. Lee, D., and Lee, G.: 'A novel over modulation technique for space vector PWM inverters', IEEE Trans. Power Electron., 1998, 13, (6),pp. 1144-1151.

[4]. N.Celanovic and D.Boroyevich (2000). 'A comprehensive study of neutral-point voltage balancing problem in three-level neutralpoint-clamped voltage source PWM inverters' - IEEE Trans. Power Electron. Vol. 15, No. 2, pp. $242-249$.

[5]. D.Hadiouche, H. Razik, and A. Rezzoug, (2000). 'Modeling of a double star induction motor for space vector PWM control' - Conf. Rec. Int. Conf. Electrical Machines (ICEM) Espoo, Finland pp. 392-396.

[6]. H. Zhang, A.V. Jouanne, S. Dai, A.K. Wallace, F.Wang, (2000). 'Multilevel Inverter Modulation Schemes to Eliminate CommonMode Voltages'- IEEE Trans on Industry Applications Vol. 36, No. 6, pp 1645-1653.

[7]. J.-H. Youm and B.-H. Kwon, 'An effective software implementation of the space-vector modulation' IEEE Trans. Ind. Electron., vol. 46, pp.866-868, Aug. 1999. 